\title{
Observação de aulas síncronas no ensino médio: contribuições para a formação de licenciandos em química
}

No ano de 2020 a educação sofreu um grande impacto no modelo de ensino em decorrência do nova coronavírus, conhecido como covid-19 (SARS-CoV-2). Este impacto provocou uma ruptura no ensino presencial e deu origem ao ensino remoto com síncronas e assíncronas. E dentro desta perspectiva o presente trabalho teve por objetivo descrever relatos de experiência de alunos do Programa Residência Pedagógica do curso de Licenciatura em Química do Instituto Federal de Educação, Ciência e Tecnologia de Rondônia (IFRO), no município de Ji-Paraná. Levando em consideração a importância do aperfeiçoamento profissional e prático dos alunos residentes e a partir da experiência da observação de aulas na escola-campo Colégio Tiradentes da Polícia Militar - CTPM VI, o objetivo do presente relato é destacar as contribuições para alunos graduandos em licenciatura a partir da observação de aulas síncronas para alunos do ensino médio na disciplina de Química. A referida atividade foi realizada durante o mês outubro de 2020 até o período de março de 2021. A observação das aulas, possibilitou a compreensão sobre postura do professor, tratamento com alunos, metodologias diversificadas além da incorporação da rotina escolar da instituição.

\section{Observing synchronous classes in high school: contributions to the training of chemistry licensees}

\begin{abstract}
In 2020, education had a great impact on the teaching model due to the new coronavirus, known as covid-19 (SARS-CoV-2). This impact caused a rupture in faceto-face teaching and gave rise to remote teaching with synchronous and asynchronous. Within this perspective, the present work aimed to describe experience reports of students from the Pedagogical Residency Program of the Chemistry Degree Course at the Federal Institute of Education, Science and Technology of Rondônia (IFRO), in the city of Ji-Paraná. Taking into account the importance of professional and practical improvement of the resident students and from the experience of observing classes at the Colégio Tiradentes da Policia Militar - CTPM VI, the objective of this report is to highlight the contributions for undergraduate students a from the observation of synchronous classes for high school students in the Chemistry discipline. This activity was carried out during the month of October 2020 until the period of March 2021. The observation of classes made it possible to understand the attitude of the teacher, treatment with students, diversified methodologies in addition to the incorporation of the institution's school routine.
\end{abstract}

Keywords: Remote teaching; Observation; Chemistry teaching; Teacher training.

Topic: Práticas, Didática e Metodologias do Ensino

Reviewed anonymously in the process of blind peer
Received: 19/04/2021

Approved: 20/07/2021
Thalia Rhaney Silva de Oliveira (iv)

Instituto Federal de Rondônia, Brasil

http://lattes.cnpq.br/7745614222689865

http://orcid.org/0000-0001-5807-7164

thaliarhaney@gmail.com

Henrique da Rocha Velôso

Instituto Federal de Rondônia, Brasil

http://lattes.cnpq.br/8153211910902231

http://orcid.org/0000-0003-2449-3033

heriquerocha@gmail.com

Geremias Dourado da Cunha (iD

Universidade Federal de Rondônia, Brasil

http://lattes.cnpq.br/1897564799872972

http://orcid.org/0000-0002-3172-5536

geremiasdarwin@gmail.com
Jusinei Meireles Stropa

Instituto Federal de Rondônia, Brasil

http://lattes.cnpq.br/5073816026052371

http://orcid.org/0000-0003-0464-3997

jusineimeireles@gmail.com
Referencing this:

OLIVEIRA, T. R. S.; VELÔSO, H. R.; CUNHA, G. D.; STROPA, J. M.

Observação de aulas síncronas no ensino médio: contribuições para a formação de licenciandos em química. Educationis, v.9, n.2, p.18-23, 2021. DOI: http://doi.org/10.6008/CBPC2318-3047.2021.002.0002 


\title{
INTRODUÇÃO
}

O estágio escolar pode ser considerado como um campo de conhecimento, assim, o estágio é produzido a partir da interação entre o curso de formação e o campo social onde as práticas foram desenvolvidas (LIMA et al., 2006).

Desde sua origem, a palavra "estágio" se relaciona com a prática de um uma determinada atividade sob supervisão, portanto, o estágio busca ensinar por meio das experiências. Além disso, o estágio permanece vinculado ao processo educativo através da Lei no 11.788/08 (COLLOMBO et al., 2016).

Para a execução do estágio escolar, há uma divisão convencional em: observação, regência coparticipativa e estágio de regência; a fase de observação se caracteriza pela presença do aluno na escolacampo e também na sala de aula, assim, poderão ser realizadas observações acerca de parte como estrutura escolar, sistema administrativo, corpo docente e metodologia adotada pelo professor (SILVA, 2016).

Acerca da observação como forma de estágio, pode-se ressaltar que:

\begin{abstract}
A observação pode contribuir para fazer a ruptura metodológica que se impõe num curso de formação de professores, entre o passado de aluno e o futuro de professor, conscientizando o aluno para a necessidade de saber observar para aprender a ensinar. Assim, aprender a observar será saber ordenar o conjunto de variáveis que se interligam no processo ensino/aprendizagem e distinguir os diversos tipos de intervenção didática e pedagógica. (SERAFINI et al., 1990)
\end{abstract}

Ainda sobre a relevância do estágio de observação na trajetória acadêmico de um licenciando, devese ressaltar que o objetivo da observação é proporcionar ao aluno a capacidade de analisar e refletir sobre a prática docente, além disso, a partir da observação o aluno adquire mais subsídios para desenvolver a regência (ROSA et al., 2012).

No ano de 2018, foi lançado, no Brasil, o Programa Residência Pedagógica do Ministério da Educação (MEC), o referido programa foi descrito em no Edital 6/2018 da Coordenação de Aperfeiçoamento de Pessoal de Nível Superior (CAPES) (FARIA et al., 2019).

O programa Residência Pedagógica oferece bolsas para alunos de cursos de licenciaturas que já tenham concluído até $50 \%$ de seu curso e buscam desenvolver atividades nas escolas-campo. 0 programa possibilita a integração dos alunos residentes, com o professor preceptor e com a escola-campo. Assim, a partir de edital de seleção, a CAPES busca selecionar IES (Instituição de Ensino Superior) que possuam curso de licenciatura para "implementação de projetos inovadores que estimulem articulação entre teoria e prática nos cursos de licenciatura, conduzidos em parceria com as redes públicas de educação básica" (CAPES, 2018).

Em meados do mês de março de 2020, a pandemia da COVID-19 (SARS-CoV2), proporcionou inúmeros impactos na sociedade, um dos setores que mais afetados foi o educacional. Devido ao avanço significativo da doença, medidas de isolamento social surgiram como medidas para minimizar a crise sanitária. A partir desses processos, houve o encerramento das aulas presenciais na rede pública de ensino, fazendo com que todo o processo de ensino fosse realizado remotamente (SARAIVA et al, 2020).

O planejamento para a continuidade das aulas de forma remota é composto por alternativas como a utilização de plataformas on-line, materiais digitais e vídeo aulas (CIEB, 2020). Assim, ainda que não haja encontros presenciais, os professores fazem uso de diferentes alternativas para que consigam permanecer 
realizando a mediação de conteúdo, seja por meio de encontros assíncronos ou síncronos (CUNHA et al, 2020).

Sobre as ferramentas síncronas utilizadas neste período, de acordo com Mendonça et al. (2019, citado por PIFFERO et al., 2020) "estas ocorrem em tempo real e seus exemplos são os chats ou teleconferências, os momentos de interação síncrona entre professores e estudante oportunizam discussões, troca de experiências e colaboração na educação à distância".

Portanto, levando em consideração a relevância da observação dentro do Estágio Supervisionado no processo formativo de licenciandos, o presente relato busca destacar as contribuições para alunos graduandos de Licenciatura em Química do Instituto Federal de Educação, Ciência e Tecnologia de Rondônia (IFRO) campus Ji-Paraná a partir da observação de aulas síncronas para alunos do ensino médio na disciplina de Química.

\section{METODOLOGIA}

A escola-campo onde as atividades do Programa de Residência Pedagógica foram realizadas foi o Colégio Tiradentes da Polícia Militar - CTPM VI, com turmas do Ensino Médio durante o período de outubro de 2020 e se estendeu até março de 2021.

De acordo com o Projeto Político Pedagógico da escola, a referida instituição escolar pública se localiza no município de Ji-Paraná/RO e possui sua gestão compartilhada, parte da SEDUC - Secretaria de Educação do Estado de Rondônia, subordinada à Coordenadoria Regional de Ensino de Ji-Paraná, e recebe diretrizes juntamente com a SESDEC - Secretaria de Estado da Segurança, Defesa e Cidadania, com a participação direta da Polícia Militar do Estado de Rondônia.

Devido à pandemia causada pela COVID-19, as atividades educacionais na escola-campo foram adaptas para o ensino remoto. Assim, a metodologia utilizada era de atividades síncronas (encontros ao vivo por plataformas, como Google Meet) e também aulas assíncronas como envio de atividades impressas ou pela plataforma online.

Dentre as atividades realizadas, destaca-se, organização do laboratório de ciências da instituição para eventual gravação e transmissão de atividade prática, acompanhamento das aulas síncronas e promoção de intervenções pontuais no processo de aprendizagem dos alunos e elaboração de atividades alternativas com uso de aplicativos.

\section{RESULTADOS E DISCUSSÃO}

Foi possível que parte dos alunos residentes pudesse visitar a escola-campo para fins de ambientação e identificação com o local de trabalho, e durante este momento, realizou-se algumas atividades como conhecer e organizar o laboratório de ciências, produzir alguns vídeos de experimentos e também sobre a estrutura e composição do laboratório.

A partir do referido processo de ambientação, os alunos residentes puderam redirecionar suas perspectivas acerca do local de atuação para a profissão docente (Figura 1). 


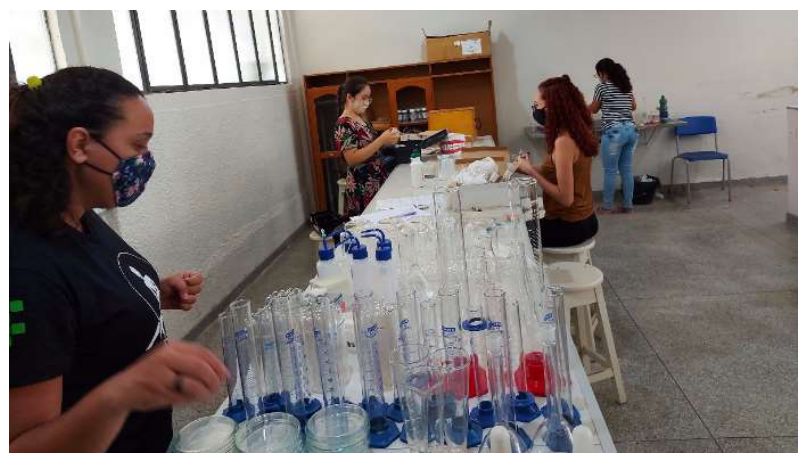

Figura 1: Ação de organização do laboratório de química da escola-campo. Ji-Paraná, RO.

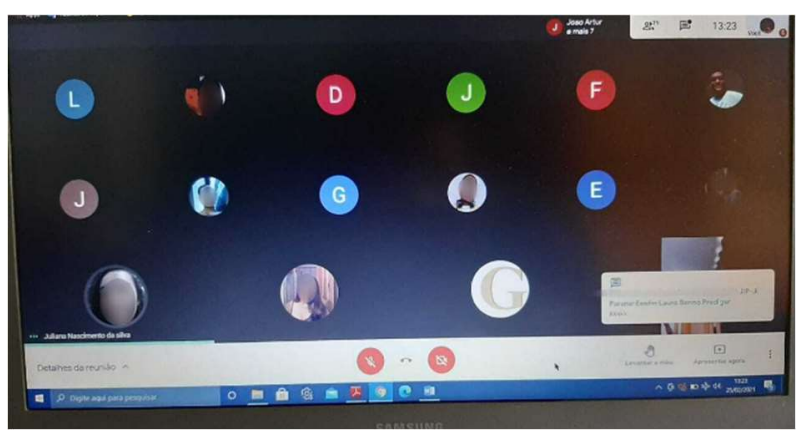

Figura 2: Imagem mostrando a ação de organização do laboratório de química da escola.

Pode-se compreender a empolgação dos alunos residentes por se ambientarem na instituição, uma vez que o estágio é um período muito importante no processo de formação de professores, pois para muitos estudantes, o contato que existia com a sala de aula era unicamente na posição de aluno, mas, a partir de atividades de estágio, os papeis se invertem e a função de professor é sentida pelos estudantes (LIMA et al., 2006). Além das visitas realizadas na escola-campo, paralelamente o professor preceptor também ministrava suas aulas síncronas por meio do Google Meet para alunos das turmas de 1ㅇ, 2ㅇ e 3ㅇan anos (Figura 2).

A observação de aulas síncronas iniciou em outubro de 2020 e se estendeu até março de 2021 de acordo com o calendário escolar da escola-campo. Um fator interessante é que a plataforma do Google Meet possibilita a interação entre o mediador, no caso das aulas, o professor e os alunos que estão participando da chamada. As aulas síncronas aconteciam semanalmente às turmas, tendo os links para acesso disponibilizados na plataforma do Google Classroom e eram divulgados nos grupos de WhatsApp das turmas. Assim também, os alunos residentes recebiam o link para acesso às salas e com isso, era possível assistir às aulas ministradas pelo professor preceptor. A partir da observação das aulas síncronas, contribuições para licenciandos em química serão pontuadas e discutidas abaixo.

\section{Rotina escolar}

Ainda que em tempos de pandemia e ensino remoto, poder realizar a atividade de observação possibilitou compreender características da rotina escolar do professor as quais se baseiam em planejamento, preparo de material e regência. Quando em sala, os alunos de cursos de licenciatura constantemente estudam sobre planejamento escolar, a importância de oferecer ferramentas que possibilitem o ensino diversificado e também sobre a postura do profissional docente em sala de aula. Quando o aluno finalmente visualiza esta realidade como parte integrante de seu processo formativo, no caso, nas atividades de residência, é um processo de infinita contribuição para a formação do aluno.

O fator visto e que merece ser destacado, é a percepção de alunos com o professor responsável pela disciplina de Química, pois é perceptível o despertar da curiosidade dos alunos acerca do que é estudado. Também, a possibilidade dos licenciandos entenderem que o processo de ensino é algo que não pode ser imutável enriquece o processo formativo dos acadêmicos, uma vez que o professor deve ser visto como uma figura que não busca meramente transmitir um conteúdo, mas aquele que objetiva despertar a vontade de 
conhecimento dos alunos. Além disso a partir da experiência de observação, tornou-se possível compreender a necessidade que professores possuem de serem profissionais motivadores, instigadores e que sejam capazes de despertar o sentimento de inquietação e vontade de saber em seus alunos.

\section{Metodologias alternativas}

A atual situação vivenciada é completamente atípica, assim, é necessário que professores criem diferentes formas para atrair a atenção de seus alunos. Durante a observação das aulas, pôde-se constatar que quando se utiliza ferramentas que vão além de aulas teóricas expositivas, os alunos participam mais. Assim, ainda que fora do ensino remoto, é interessante levar em consideração estes fatos para a ministração de aulas presenciais também.

Nas aulas síncronas ministradas pelo professor preceptor houve a utilização de games, como o Kahoot e houve apresentação de softwares educacionais. Além disso, o professor incentivava os alunos a gravarem vídeos caseiros realizando experimentos de química que fossem de simples preparo, com materiais domésticos. Desta forma, como os alunos não tinham a possibilidade de realizar experimentos no laboratório, podiam ser os próprios cientistas em suas casas.

Os referidos tipos de experiência servem de exemplo para a futura prática docente dos alunos de cursos de licenciatura, uma vez que possibilitar a aplicação de metodologias diversificadas aos estudantes abre um leque de possibilidades de questionamentos e incentiva a participação dos alunos. Assim, a observação de aplicação de diferentes métodos em aulas síncronas contribui para a percepção de alternativas de ensino para licenciando, fazendo com que ele tenha conhecimento de outras possibilidades para o ensino de diferentes conteúdos.

\section{Contextualização dos conteúdos}

Durante o processo formativo em cursos de licenciatura, muito se lê sobre a contextualização de conteúdo. Ao se tratar da disciplina de química, é necessário que o processor esteja preparado para tornar o assunto trabalhado na aula em algo que se faça presente na vida dos alunos. Estes pontos foram observados durante as aulas síncronas, por inúmeras vezes a fala do professor-preceptor se baseava em exemplificações sobre o conteúdo no cotidiano dos alunos que assistiam àquela aula.

Ao contextualizar o que está explicando, o aluno compreende a partir do que ele já conhece e entende os conceitos do tema em estudo específico (SILVA, 2007). Assim, demonstra-se a eficácia de contextualizar um determinado conteúdo com o cotidiano do estudante, portanto, esta é uma prática de extrema importância para a ministração de aulas. Além disso, um outro ponto interessante que pôde-se observar foi que a partir de contextualizações dos conteúdos, os alunos sentiam-se encorajados e despertados a questionar sobre o assunto que estava sendo estudado.

Entender a importância da contextualização de conteúdo a partir de constatação realizada por meio da observação contribui para que futuros professores agreguem esta prática em suas futuras atuações, visto que ela funciona como uma importante ferramenta para o ensino inclusivo e diversificado para os alunos. 


\section{CONCLUSÕES}

A observação das aulas síncronas ministradas na disciplina de Química pelo professor preceptor possibilitou a compreensão de como é a realidade escolar. $O$ fato de o processo de observação ter sido realizado em tempos de pandemia, fazendo com que o ensino fosse feito apenas remotamente, tornou possível compreender o quanto o professor deve ser um profissional flexível.

A observação das aulas de Química, ainda que tenham sido feitas remotamente, foi capaz de agregar valores extremamente significativos para a formação do licenciando em Química, uma vez que por mais que a experiência não tenha sido desenvolvida presencialmente, todo o processo demonstrou pilares essenciais que futuros profissionais da educação devem ter consciência, como a postura de um professor, a utilização de diferentes métodos para o ensino de um determinado conteúdo, como é o preparo do professor para a execução de suas aulas e também sobre as dificuldades enfrentadas na rotina escolar por parte dos professores.

\section{REFERÊNCIAS}

CAPES. Coordenação de Aperfeiçoamento de Pessoal de Nível Superior. Edital 6: Chamada Pública para apresentação de propostas no âmbito do Programa de Residência Pedagógica. 2018. Brasília: Ministério da Educação, 2018.

CIEB. Planejamento das secretarias de educação do Brasil para ensino remoto. São Paulo, 2020.

COLLOMBO, I. M.; BALLÃO, C. M.. Histórico e aplicação da legislação de estágio no Brasil. Educar em Revista, n.53, p.171-186, 2014.

CUNHA, L. F. F.; SILVA, A. S.; SILVA, A. P.. O ensino remoto no Brasil em tempos de pandemia: diálogos acerca da qualidade e do direito e acesso à educação. UNB, 2020.

FARIA, J. B.; DINIZ-PEREIRA, J. E.. Residência pedagógica: afinal, o que é isso?. Revista de Educação Pública, v.28, n.68, p.333-356, 2019.

LIMA, M. S. L.; PIMENTA, S. G.. Estágio e docência: diferentes concepções. Poíesis pedagógica, v.3, n.3-4, p.5-24, 2006.

PIFFERO, E. L. F.; COELHO, C. P.; SOARES, R. G.; ROEHRS, R.. Metodologias ativas e o ensino remoto de Biologia: uso de recursos online para aulas síncronas e assíncronas. Research, Society and Development, v.9, n.10, p.e719108465-e719108465, 2020.

ROSA, J. K. L.; WEIGERT, C.; SOUZA, A. C. G. A.. Formação docente: reflexões sobre o estágio curricular. Ciência \& Educação, Bauru, v.18, n.3, p.675-688, 2012.

SARAIVA, K.; TRAVERSINI, C. S.; LOCKMANN, K.. A educação em tempos de COVID-19: ensino remoto e exaustão docente. Práxis Educativa, Ponta Grossa, v.15, e2016289, p.1-24, 2020.

SERAFINI, Ó.; PACHECO, J. A.. A observação como elemento regulador da tomada de decisões: a proposta de um instrumento. Revista Portuguesa de Educação, v.3, n2, p.119, 1990.

SILVA, E. L.. Contextualização no ensino de química: ideias e proposições de um grupo de professores. 2007.

SILVA, K. C. M. O.. Estágio supervisionado na formação inicial de professores: o dito e o não dito nos PPC de licenciatura em química. Dissertação (Mestrado em Educação em Ciências e Matemática) - Universidade Federal de Goiás, Goiânia, 2016.

A CBPC - Companhia Brasileira de Produção Científica (CNPJ: 11.221.422/0001-03) detém os direitos materiais desta publicação. Os direitos referem-se à publicação do trabalho em qualquer parte do mundo, incluindo os direitos às renovações, expansões e disseminações da contribuição, bem como outros direitos subsidiários. Todos os trabalhos publicados eletronicamente poderão posteriormente ser publicados em coletâneas impressas sob coordenação da Sustenere Publishing, da Companhia Brasileira de Produção Científica e seus parceiros autorizados. Os (as) autores (as) preservam os direitos autorais, mas não têm permissão para a publicação da contribuição em outro meio, impresso ou digital, em português ou em tradução. 